\title{
Effects of Aerobic Exercise on Disease Severity and Walking Ability in Patients with Parkinson's Disease
}

\author{
Dae-Hyouk Bang ${ }^{1}$, Hyeon-Jeong Noh ${ }^{2}$ \\ 'Department of Physical Therapy, Oriental Hospital, WonKwang University, Iksan; ${ }^{2}$ Department of Rehabilitation Center, Design Hospital, Jeonju, \\ Korea
}

Purpose: This study was conducted to explore the effects of aerobic exercise on the severity of disease and walking ability in patients with Parkinson's disease.

Methods: Twelve patients with Parkinson's disease participated in the study. Participants were randomly assigned to either an aerobic exercise group $(n=6)$ or a self-exercise group $(n=6)$. All participants underwent treadmill training for 30 minutes. In addition, the experimental group (aerobic exercise group) and control group (self-exercise group) participated in a 30 minutes exercise program. In both groups, exercise was performed five times a week for four weeks. Outcome including disease severity (Unified Parkinson's Disease Rating Scale) and walking ability ( $10 \mathrm{~m}$ walking speed test, 6 minutes walking test, timed up-and-go test) were measured at baseline and after 4-weeks.

Results: Significant differences in disease severity and walking ability were observed between the pre- and post-exercise groups $(p<0.05)$. The improvement of disease severity and walking endurance was significantly higher in the experimental group than in the control group $(p<0.05)$.

Conclusion: These findings demonstrate that aerobic exercise is effective at improving disease severity and walking endurance in patients with Parkinson's disease.

Keywords: Aerobic exercise, Disease Severity, Parkinson's, Walking

서 론

파킨슨병(Parkinson's disease)은 뇌의 기저핵(basal ganglia)에서 도파 민(dopamine) 생성에 관여하는 신경세포의 감소와 기능 저하로 균형, 자세조절, 움직임의 속도, 자세 변화에 반응하는 능력이 감소되는 질 환이다. 질환이 진행됨에 따라 강직(stiffness), 안정시 떨림(resting tremor), 운동완서(bradykinesia), 보행능력 감소 등과 같이 점진적 운 동기능의 저하 증상을 보이며 신체활동 능력의 감소로 독립적인 삶 의 능력이 제한되는 퇴행성 뇌 질환이다. ${ }^{2}$ 파킨슨병은 주로 노인에게 서 발병되며, 남자가 여자보다 $3: 2$ 의 비율로 고령의 남성이 상대적으 로 높은 발병률을 보이는 특징이 있다. ${ }^{3}$

보행은 인간이 생활하기 위한 가장 기본적인 움직임이며, 평생 동 안 가장 많이 수행하는 움직임중의 하나이다. 또한, 보행은 속도뿐만 아니라 걸음의 형태나 태도 등을 의미한다. 파킨슨병 환자의 보행은 신체의 가동성이 점차 감소하여 움직임을 시작하는 것이 매우 어려
워 지며, 보폭이 짧고 빠른 발의 움직임을 몇 차례 시도 후 보행을 시 작하며 보행이 시작되면 멈추기가 어려운 조절장애를 보인다. 질환 이 진행됨에 따라 몸통이 굴곡형태로 변하게 되며 사지의 움직임이 갈수록 느려지며 보행 시 팔을 흔드는 움직임도 감소되어 낙상의 빈 도가 증가 하게 된다. ${ }^{5}$ 지역사회 보행을 하기 위한 보행능력 즉 보행 속도, 균형능력, 보행 지구력은 매우 밀접한 관계를 가지고 있다. ${ }^{6}$ 균 형 능력의 감소는 보행 속도의 향상에 저해요인으로 작용하며, 보행 지구력의 감소 또한 지속적인 보행과 지역사회 활동의 제한요인으로 작용한다. ${ }^{4}$ 따라서, 보행능력의 향상을 위해서는 보행속도, 균형능력, 보행 지구력의 전반적인 향상을 가져와야 한다.

파킨슨병의 가장 효과적인 관리방법은 약물요법과 신체활동을 지 속적으로 하게 하는 것이다. 약물요법만으로는 파킨슨병 환자의 균 형이나 자세불안등과 같이 움직임 장애문제를 해결할 수 없다. 선행 연구에서 트레드밀(treadmill)을 이용한 보행 훈련은 반복적인 보행 훈련이자 과제 지향적 훈련(task-oriented training)으로 파킨슨병 환자 
의 보행능력을 향상시킨다고 보고하였다. ${ }^{8,9} \mathrm{Bang}$ 등 ${ }^{4}$ 은 트레드밀 훈 련은 일종의 강제 사용(force use)의 한 형태로 보행속도와 보행지구력 의 양적인 면과 보행 형태인 질적인 면을 모두 향상 시킬 수 있는 방법 이라고 보고하였다.

최근 연구들에서 신경계질환 환자의 기능향상을 위한 방법으로 유산소운동과 순환식 과제훈련(circuit training)방법이 효과적인 방 법으로 제시되고 있다. ${ }^{1,2,10}$ 이 중 유산소운동은 선행연구 ${ }^{11}$ 에서 파킨 슨병 환자의 운동신경 퇴행을 지연시켜 기능적 변화를 완화시킨다고 보고하였다. 또한, 유산소운동은 잠재적으로 신경세포의 괴사를 감 소시키고 세포의 생존을 향상시켜 신경발생을 자극하고 세포의 단 백질 함량수준을 향상시킨다고 보고하였다. ${ }^{2}$ 이와 같이 유산소운동 은 파킨슨병 환자의 신체기능향상을 위해 추천되고 있으나 아직 국 내에서 연구가 부족한 실정이며, 유산소운동이 질병 정도와 보행능 력의 향상에 어떠한 영향을 미치는지 알아보는 것은 중요한 문제이 다. 따라서 본 연구는 트레드밀을 이용한 보행 훈련과 추가적으로 시 행한 고정식 자전거를 이용한 유산소운동이 파킨슨병 환자의 질병 정도와 보행능력에 어떠한 영향을 미치는지 알아보고자 한다.

\section{연구 방법}

\section{1. 연구대상}

본 연구의 대상자들은 파킨슨병 환자로 6개월 이상 지역내의 대학병 원이나 재활병원의 외래를 이용하고 있는 12 명을 대상으로 하였다. 모든 대상자들은 병원에서 처방해준 약물을 복용하는 상태였으며, 실험이 진행되는 상태에서도 복용하도록 하였다. 대상자들은 제비 뽑기를 통한 무작위 선별로 실험군과 대조군으로 배정하였다. 대상 자들은 질병 등급(Hoehn-Yahr scale) 2단계인 경증의 파킨슨병 환자 로 독립보행이 가능한 대상자이며, 의사소통과 연구자의 지시에 적 절하게 따를 수 있는 사람으로 연구참여에 관한 충분한 설명을 듣고 연구 참여에 동의한 대상자를 선정하였다.

\section{2. 측정도구}

\section{1) 질병 정도(Disease severity)}

질병 정도의 변화를 알아보기 위하여 파킨슨병 평가 척도(unified Parkinson's disease rating scale, UPDRS)를 이용하였다. 파킨슨병 평가 척도는 크게 4 개의 부분으로 나누어진다. ${ }^{12}$ UPDRS- 1 은 일상생활의 비운동성 경험으로 정신검사에 해당하며, UPDRS-2는 일생생활활 동, UPDRS-3은 운동기능검사, UPDRS-4는 운동기능과 관련된 합병 증을 평가하는 항목으로 구성되어있다. 본 연구에서는 중재에 따른 일생생활활동과 운동기능의 변화를 알아보기 위하여 일상생활활동 과 운동기능검사를 평가하였다. 본 평가는 점수가 높을수록 질병의
정도가 심한 것으로 평가된다.

\section{2) 보행속도 검사}

$10 \mathrm{~m}$ 보행속도 검사 $(10 \mathrm{~m}$ walking speed test, $10 \mathrm{MWT})$ 는 치료실에서 보행속도를 평가하는데 매우 유용한 방법으로 편안한 보행과 빠른 보행으로 $14 \mathrm{~m}$ 를 걷게 하여 가속기간과 감속기간인 시작과 끝 범위 2 $\mathrm{m}$ 를 제외한 중간 $10 \mathrm{~m}$ 거리에 대한 시간을 측정하였다. 본 연구에서 는 대상자가 편안한 보행을 하는 동안 시간을 측정하였다. 검사 시행 전 대상자는 먼저 한번 걷게 하여 적응하도록 한 후 3 회 실시하여 평 균시간을 구하였다. 이때 치료사는 환자의 뒤를 따라가면서 안전을 확보하였다.

\section{3) 보행지구력 검사}

6분 보행검사(6-minute walking test, $6 \mathrm{MWT}$ )는 6 분 동안 최대로 걸을 수 있는 거리를 측정하는 보행지구력 평가 방법이다. ${ }^{13}$ 운동장의 200 $\mathrm{m}$ 트랙에 $1 \mathrm{~m}$ 마다 표시를 해놓고 치료사가 시계로 6 분을 입력한 후 출발과 동시에 시계를 눌러 6 분동안 대상자가 걸은 총 거리를 계산 하였다. 측정은 대상자가 트랙을 돈 횟수에 대한 거리와 출발선부터 테이프의 거리를 합하여 기록하였다.

\section{4) 동적 균형검사}

일어나 걸어가기 검사(timed up-and-go test, TUG)는 운동성과 균형을 빠르게 측정할 수 있는 검사방법으로 특히, 보행을 하여 장애물을 회 전하고 돌아오는 과제를 수행하는 평가를 하는데 유용하다. 팔걸이 가 있는 $47 \mathrm{~cm}$ 높이의 의자에서 일어나 $3 \mathrm{~m}$ 를 걸어간 뒤 표시해둔 부 분에서 다시 돌아와 의자에 앉는 동작을 수행하는 동안 소요된 시간 을 초 시계를 이용하여 기록하였다. 검사는 총 3 회 반복 수행하여 측 정한 값의 평균을 구하였다. ${ }^{14}$

\section{3. 중재방법}

본 연구의 모든 대상자는 30 분의 트레드밀 보행훈련을 하루에 30 분 씩, 주 5회 받았다. 대상자의 상태에 따라 트레드밀 보행 속도는 대상 자가 편안하게 할 수 있는 속도를 측정하여 무리가 가지 않는 정도에 서 시작하였다. 처음에는 트레드밀을 지속적으로 탈 수 없는 대상자 들은 2 분에서 4 분정도 훈련 후 휴식을 주고 다시 훈련을 진행하였다. 대상자가 훈련이 진행됨에 따라 보행속도를 증가시켜도 훈련을 지속 할 수 있을 시 속도를 높여 진행하였다. 치료사가 뒤에 위치하여 대상 자가 안전하고 편안한 상태에서 트레드밀을 탈 수 있도록 유도하였 다. 트레드밀은 보행능력에 따라 환자 스스로 속도를 조절할 수 있도 록 계기판이 부착되어 있으며, 양 옆쪽과 전방에는 안전 손잡이가 장 착되어 있어 훈련 중 균형을 잃을 경우 손으로 잡을 수 있도록 되어있 
다. 훈련 중 전방 계기판과 거리가 일정거리 벌어지면 멈추게 설계된 탈, 부착 센서가 달린 고리가 연결되어 있다. 훈련 중 최대한 손을 잡 지 않고 팔을 흔들어 걷게 유도하였다. ${ }^{4}$ 모든 대상자들은 훈련 전 5 분 정도 스트레칭을 실시하였으며, 훈련이 끝난 후 심호흡과 간단한 스 트레칭으로 훈련을 마무리하였다.

실험군은 추가적으로 고정식 자전거를 이용하여 유산소 운동을 30 분, 주 5 회, 4 주간 시행하였다. 훈련이 시작되기 전에 대상자들의 최 대 맥박수치를 맥박측정기(Pulse Oximeter, Contec Medical System Co., China)를 이용하여 기록하였으며, 고정식 자전거를 타는 동안 실 험군은 최대 맥박의 $50-80 \%$ 를 유지하도록 하였다. ${ }^{5}$ 훈련 시작 후 환 자가 피로감이나 통증 호소, 호흡이상, 안색의 변화 등을 보이면 즉시 훈련을 중지하였다.

대조군은 추가적으로 30 분간 근력 운동, 몸통의 유연성을 향상시 키는 스트레칭, 균형능력을 향상시킬 수 있는 운동, 그리고 보행훈련 중 본인이 원하는 운동을 하도록 하였다.

\section{4. 분석방법}

본 연구의 실험에서 수집된 자료는 윈도우용 SPSS 18.0 프로그램을 이용하여 통계 분석하였다. 연구대상자들의 일반적인 특성은 평균가

Table 1. General characteristics of the subjects

\begin{tabular}{lccc}
\hline & $\begin{array}{c}\text { Aerobic exercise } \\
\text { group }(n=6)\end{array}$ & $\begin{array}{c}\text { Control } \\
\text { group }(n=6)\end{array}$ & p-value \\
\hline Sex (n) & 3 & 2 & 0.56 \\
Men & 3 & 4 & \\
Women & $56.63 \pm 6.00^{\mathrm{a}}$ & $58.50 \pm 6.82$ & 0.26 \\
Age (year) & $163.00 \pm 10.03$ & $159.33 \pm 9.20$ & 0.69 \\
Height (cm) & $63.83 \pm 9.28$ & $62.00 \pm 6.16$ & 0.34 \\
Weight (kg) & $16.50 \pm 5.54$ & $15.67 \pm 3.61$ & 0.81 \\
Disease duration (month) & $28.33 \pm 1.03$ & $27.67 \pm 1.04$ & 0.35 \\
MMSE (s) & & & \\
\hline
\end{tabular}

Significance level at $\mathrm{p}<0.05$ for difference between the groups. MMSE: mini-mental state examination.

${ }^{\mathrm{a} M e a n} \pm$ SD.
표준편차를 구하기 위해 기술통계를 시행하였다. 그룹 내의 중재 전 후의 질병의 정도, 보행속도, 보행지구력과 동적 균형능력의 차이를 비교하기 위하여 윌콕슨 부호 순위 검증(Wilcoxon signed-rank test)를 시행하였다. 그룹 간 중재 전과 중재 후 방법에 따른 차이를 비교하기 위하여 맨-휘트니 유-검증(Mann-Whitney U-test)을 사용하였다. 모든 변인에 대한 통계학적 유의수준은 0.05 로 설정하였다.

\section{결 과}

본 연구에 참여한 총 12 명의 대상자들은 모든 실험과정을 마쳤으며, 대상자들의 일반적인 특징은 Table 1과 같다. 실험군인 트레드밀 보행 과 유산소 훈련을 시행한 유산소 훈련군은 총 6명이며, 평균 발병일 은 16.5 개월, 평균 연령은 56.6 세, 평균 한국형 간이 정신상태검사는 28.3점이다. 대조군인 트레드밀 보행훈련만 시행한 군은 총 6명이며, 평균 발병일은 15.7 개월, 평균 연령은 58.5 세, 평균 한국형 간이 정신 상태검사는 27.7 점이다. 연구대상자의 일반적 특성에 대한 두 그룹 간 유의한차이는 없었다 $(\mathrm{p}>0.05)$.

중재 전 두 그룹 간 질병 정도(UPDRS-2 ( $\mathrm{z}=-0.652, \mathrm{p}=0.514)$, UPDRS-3 ( $\mathrm{z}=-0.564, \mathrm{p}=0.572))$, 보행속도 $(\mathrm{z}=0.00, \mathrm{p}=1.00)$, 보행지구력 $(\mathrm{z}=-0.808, \mathrm{p}=0.419)$ 과 동적 균형 $(\mathrm{z}=-0.401, \mathrm{p}=0.669)$ 의 사전 평가 값 은 유의한 차이를 보이지 않았다 $(\mathrm{p}>0.05)$. 중재 후 질병 정도(UPDRS-2, UPDRS-3), 보행속도, 보행지구력과 동적 균형에서 실험군과 대조군 모두 유의한 변화를 보였다 $(\mathrm{p}<0.05)$. 중재 후 실험군과 대조 군 비교에서 질병 정도(UPDRS-2, UPDRS-3)와 보행지구력은 실험군 이 대조군보다 더 유의한 차이를 보였지만 $(\mathrm{p}<0.05)$, 보행속도와 동적 균형능력에서는 유의한 차이를 보이지 않았다 $(\mathrm{p}>0.05)$ (Table 2).

\section{고 찰}

파킨슨병은 약물요법으로 치료를 하고 있으나, 파킨슨병 환자는 여 전히 기능적 활동, 보행과 균형의 문제를 가지고 있다. ${ }^{16}$ 이러한 문제

Table 2. Comparison of outcome measures

\begin{tabular}{|c|c|c|c|c|c|}
\hline \multirow{2}{*}{ Variables } & \multicolumn{2}{|c|}{ Aerobic exercise group $(n=6)$} & \multicolumn{2}{|c|}{ Control group $(n=6)$} & \multirow{2}{*}{$\begin{array}{c}\text { Between groups } \\
\text { Z }\end{array}$} \\
\hline & Pre-test & Post-test & Pre-test & Post-test & \\
\hline UPDRS-2(s) & $15.00 \pm 2.61^{a}$ & $9.83 \pm 2.32^{\star \dagger}$ & $15.83 \pm 2.48$ & $13.33 \pm 2.58^{\star}$ & -2.016 \\
\hline UPDRS-3(s) & $20.83 \pm 3.13$ & $13.83 \pm 1.47^{\star \dagger}$ & $21.84 \pm 2.64$ & $17.67 \pm 2.16^{\star}$ & -2.576 \\
\hline 10MWT(sec) & $14.12 \pm 1.57$ & $10.06 \pm 1.19^{\star}$ & $14.19 \pm 2.16$ & $11.32 \pm 1.11^{\star}$ & -1.922 \\
\hline $6 \mathrm{MWT}(\mathrm{m})$ & $251.33 \pm 52.65$ & $318.00 \pm 41.21^{\star \dagger}$ & $229.50 \pm 46.96$ & $255.17 \pm 43.45^{\star}$ & -2.085 \\
\hline TUG(sec) & $13.45 \pm 2.46$ & $9.07 \pm 1.96^{\star}$ & $14.29 \pm 2.55$ & $10.64 \pm 2.22^{\star}$ & -1.043 \\
\hline
\end{tabular}

UPDRS: unified Parkinson's disease rating scale, UPDRS-2: section of activities of daily living in UPDRS, UPDRS-3: section of motor examination in UPDRS, 10 MWT: 10 m walking test, 6 MWT: 6-minute walking test, TUG: timed up-and-go test. *Significant difference within groups, 'Significant difference between groups. a Means $\pm S D$ 
들을 해결하기 위하여 약물요법과 병행하여 다양한 중재방법들이 시행되고 있다. 이 중 본 연구에서는 파킨슨병 환자의 보행능력 향상 에 효과적이라고 보고된 트레드밀 보행훈련을 시행하였다. 하지만 파킨스병은 단순한 신체활동의 반복적인 연습으로 전반적인 보행능 력을 증진시키는데 한계가 있다. 최근 유산소 운동이 파킨슨병 환자 의 운동신경 퇴행을 지연시킴으로써 기능 변화를 완화시킨다고 하 였다. ${ }^{2}$ 또한, 잠재적으로 신경세포의 생존을 향상시켜 신경발생을 자 극하고 세포의 단백질 함량수준을 향상시킨다고 보고되고 있다.10 이 에 본 연구는 파킨슨병 환자들에게 트레드밀 보행 훈련과 유산소운 동을 통하여 파킨슨병의 질병 정도와 보행능력에 어떠한 영향을 미 치는지 알아보고자 본 연구를 시행하였다. 본 연구 결과 보행훈련과 유산소운동을 병행한 실험군에서 질병 정도의 감소와 보행 능력 중 보행 지구력의 향상에 도움이 되는 것으로 나타났다.

본 연구에서 파킨슨병 환자의 질병 정도와 보행능력의 변화를 알 아보기 위하여 평가에 적합하고 평가 민감도가 높아 기능적인 변화 를 세밀하게 반영할 수 있는 파킨슨병 평가 척도, $10 \mathrm{~m}$ 보행속도 검사, 6 분 보행 검사와 일어나서 걷기 검사를 사용하였다. ${ }^{8.17}$ 이 평가 방법 들은 임상에서 환자의 동작을 관찰, 시간 측정, 또는 실제로 걷는 거 리를 측정하는 검사방법으로 임상적 측면에서 측정이 간단하며 용 이하여 회복 정도와 지역사회로의 복귀를 예측하는데 유용한 도움 이 될 수 있는 측정 방법을 사용하였다. 이 중 파킨슨병 평가 척도는 정신검사, 일생생활활동, 운동기능검사, 운동기능과 관련된 합병증 의 4 가지 항목으로 구성되어 있으며, 이 중 물리치료영역과 밀접한 연 관이 있는 일상생활활동(UPDRS-2)과 운동기능검사(UPDRS-3)를 측 정하여 중재에 따른 파킨슨병의 질병 정도 변화를 측정하기 위하여 사용하였다.

Pohl 등18은 파킨슨병 환자에게 트레드밀을 이용한 보행훈련이 트 레드밀 없이 보행훈련을 시행한 군보다 보행능력 향상에 효과적이라 고 보고하였다. 트레드밀을 이용한 보행 훈련은 파킨슨병 환자의 보 폭을 강제적으로 늘려 보행향상에 매우 중요한 인자로 작용한다고 보고하였다. 본 연구 결과 파킨슨병 환자에게 트레드밀 훈련은 질병 정도 감소와 보행능력 향상에 효과적인 것임을 다시 확인하였다. 실 험군과 대조군 모두에게 시행한 트레드밀 훈련은 파킨슨병 환자의 질병 정도를 측정하는 파킨슨병 평가 척도 중 일상생활활동과 운동 기능검사와 관련된 부분에서 실험 전보다 실험 후 유의한 향상을 보 였다. 또한, 보행능력의 변화를 알아보기 위해 시행한 보행 속도, 보행 지구력, 일어서서 걷기 검사에서도 모두 유의한 향상을 보였다. 이는 파킨슨병 환자의 질병 정도 감소와 보행능력 향상에 트레드밀 훈련 이 효과적이라는 선행연구들의 연구 결과와 유사하다.19.20 Miyai 등 ${ }^{21}$ 은 트레드밀 훈련을 이용한 파킨스병 환자의 보행능력 향상은 반복 적 사용을 통한 대뇌피질의 보완운동영역의 활성화 기전이라고 하였
다. 하지만, 실험군과 대조군 비교시 보행속도와 동적 균형능력에서 는 유의한 차이를 보이지 않았다. 이는 트레드밀 훈련이 두 군의 보행 속도와 동적 균형능력의 향상에는 영향을 미쳤지만, 유산소운동이 보행속도와 동적 균형능력의 향상에는 영향을 주지 못한 것으로 사 료된다.

최근에는 신경계손상 환자에게 유산소운동이 적극 권장되고 있 다. 이는 심폐기능이 자발적 회복이 이루어 지지 않아 일상생활로 복 귀를 위해서는 반드시 유산소능력에 대한 중재 프로그램을 시행해 야만 한다.22 미국심장협회는 유산소운동을 회당 20-60분, 주 3-7일 정도를 권장하고 있다. ${ }^{23}$ 본 연구에서도 미국심장협회에서 권고하는 유산소운동의 범위에서 시행하였으며, 이는 실험군의 파킨슨 질병척 도를 이용한 질병 정도의 감소와 보행지구력은 대조군에 비해 유의 한 차이를 보인 결과에 영향을 미쳤을 것으로 사료된다. 하지만, Tang 등 $^{24}$ 의 연구에서는 실험군과 대조군의 유의한 차이를 보이지 않았다. 본 연구와 선행 연구결과가 다른 이유는 선행 연구는 낮은 강도로 유 산소운동을 시행하였지만, 본 연구는 최대 심박수의 50-80\%을 유지 하면서 유산소운동을 시행하였기 때문이라고 사료된다. 이러한 강도 의 유산소운동은 파킨슨병 환자의 뇌유리신경성장인자(brain-derived neurotrophic factor, BDNF), 아교세포신경성장인자(glial-derived neurotrophic factor, GDNF), 인슐린(insulin)과 같은 성장인자, 도파민 (dopamine)과 세로토닌(serotonin) 같은 신경전달물질의 신경성장인 자를 증가시켜 운동기능의 향상과 파킨슨병 증상의 감소를 유도한 다고 하였다. ${ }^{10,11,25}$

본 연구의 결과 파킨슨병 환자의 질병 정도 감소와 보행지구력의 향상을 위하여 유산소운동이 효과를 제시해주는 것이다. 이러한 결 과는 유산소운동이 심폐기능에만 관여하는 것이 아니라 파킨슨병 환자의 증상 감소와 지연에 도움이 될 수 있다는 것을 의미한다. 이는 파킨슨병 환자의 증상 감소와 보행지구력 향상을 통한 일상생활수 행능력의 향상과 사회참여의 기회를 줄 수 있는 효과적인 방법이 될 수 있을 것이다. 하지만, 본 연구에서 적은 대상자의 수와 단기간의 중 재로 연구결과를 모든 파킨슨병 환자들에 대한 보편화시키기는 힘 들다. 하지만, 유산소운동 방법으로 사용한 고정식 자전거는 일반 병 원에서 흔히 사용하는 기구로 운동 강도에 대한 개념을 이해하고 대 상자에게 적절한 중재를 적용한다면 운동의 효과를 얻을 수 있을 것 이다. 향후 연구에서는 파킨슨병 환자에게 다양한 유산소운동 방법 을 고려하여 가장 효과적인 유산소운동 방법을 이용한 재활이 이루 어져야 할 것이다. 또한, 연구의 대상자들이 경증의 파킨슨병 증상을 보이는 대상자들이므로 증상의 정도에 따른 효과를 알아보는 연구 가 진행되어야할 것이다. 


\section{REFERENCES}

1. Cakit BD, Saracoglu M, Genc H et al. The effects of incremental speeddependent treadmill training on postural instability and fear of falling in parkinson's disease. Clin Rehabil. 2007;21(8):698-705.

2. Monteiro EP, Franzoni LT, Cubillos DM et al. Effects of nordic walking training on functional parameters in parkinson's disease: A randomized controlled clinical trial. Scand J Med Sci Sports. 2016.

3. Kim MY, Kim CH, Lim BO. The effect of 12-week exercise program on freezing of gait in patients with parkinson's disease. Kor J Phys Edu. 2014;53(3):739-47.

4. Bang DH, Shin WS, Kim SY et al. The effects of action observational training on walking ability in chronic stroke patients: A double-blind randomized controlled trial. Clin Rehabil. 2013;27(12):1118-25.

5. Morris ME, Huxham F, McGinley J et al. The biomechanics and motor control of gait in parkinson disease. Clin Biomech (Bristol, Avon). 2001; 16(6):459-70.

6. Lee KS, Choe HS, Lee JH. Influence of visual feedback training on the balance and walking in stroke patients. J Kor Phys Ther. 2015;27(6):40712.

7. Bloem BR, Grimbergen YA, Cramer M et al. Prospective assessment of falls in parkinson's disease. J Neurol. 2001;248(11):950-8.

8. Abbruzzese G, Marchese R, Avanzino L et al. Rehabilitation for parkinson's disease: Current outlook and future challenges. Parkinsonism Relat Disord. 2016;22 Suppl 1:S60-4.

9. Tseng IJ, Yuan RY, Jeng C. Treadmill training improves forward and backward gait in early parkinson disease. Am J Phys Med Rehabil. 2015; 94(10):811-9.

10. Frazzitta G, Balbi P, Maestri R et al. The beneficial role of intensive exercise on parkinson disease progression. Am J Phys Med Rehabil. 2013; 92(6):523-32.

11. Tuon T, Valvassori SS, Dal Pont GC et al. Physical training prevents depressive symptoms and a decrease in brain-derived neurotrophic factor in parkinson's disease. Brain Res Bull. 2014;108:106-12.

12. Hauser RA, Abler V, Eyal E et al. Efficacy of rasagiline in early parkinson' s disease: A meta-analysis of data from the tempo and adagio studies. Int J Neurosci. 2016:1-5.

13. Lista Paz A, Gonzalez Doniz L, Ortigueira Garcia S et al. Respiratory muscle strength in chronic stroke survivors and its relation with the 6-minute walk test. Arch Phys Med Rehabil. 2016;97(2):266-72.
14. Mehrholz J, Wagner K, Rutte K et al. Predictive validity and responsiveness of the functional ambulation category in hemiparetic patients after stroke. Arch Phys Med Rehabil. 2007;88(10):1314-9.

15. Sandberg K, Kleist M, Falk L et al. Effects of twice-weekly intense aerobic exercise in early subacute stroke: A randomized controlled trial. Arch Phys Med Rehabil. 2016.

16. Ahlskog JE. New and appropriate goals for parkinson disease physical therapy. JAMA Neurol. 2016;73(3):269-70.

17. Yu KH, Jeon HS. The effect of dual-task gait training on gait performance under cognitive tasks in chronic stroke. J Kor Phys Ther. 2015; 27(5):364-8.

18. Pohl M, Rockstroh G, Ruckriem S et al. Immediate effects of speed-dependent treadmill training on gait parameters in early parkinson's disease. Arch Phys Med Rehabil. 2003;84(12):1760-6.

19. Ganesan M, Sathyaprabha TN, Pal PK et al. Partial body weight-supported treadmill training in patients with parkinson disease: Impact on gait and clinical manifestation. Arch Phys Med Rehabil. 2015;96(9): 1557-65.

20. Mehrholz J, Kugler J, Storch A et al. Treadmill training for patients with parkinson's disease. Cochrane Database Syst Rev. 2015;8:CD007830.

21. Miyai I, Fujimoto Y, Ueda Y et al. Treadmill training with body weight support: Its effect on parkinson's disease. Arch Phys Med Rehabil. 2000; 81(7):849-52.

22. Danielsson A, Sunnerhagen KS. Oxygen consumption during treadmill walking with and without body weight support in patients with hemiparesis after stroke and in healthy subjects. Arch Phys Med Rehabil. 2000; 81(7):953-7.

23. Gordon NF, Gulanick M, Costa F et al. Physical activity and exercise recommendations for stroke survivors: An american heart association scientific statement from the council on clinical cardiology, subcommittee on exercise, cardiac rehabilitation, and prevention; the council on cardiovascular nursing; the council on nutrition, physical activity, and metabolism; and the stroke council. Stroke. 2004;35(5):1230-40.

24. Tang A, Sibley KM, Thomas SG et al. Effects of an aerobic exercise program on aerobic capacity, spatiotemporal gait parameters, and functional capacity in subacute stroke. Neurorehabil Neural Repair. 2009;23(4): 398-406.

25. Murray DK, Sacheli MA, Eng JJ et al. The effects of exercise on cognition in parkinson's disease: A systematic review. Transl Neurodegener. 2014; 3(1):5. 